\title{
Obsessive compulsive disorder
}

\section{J Stein}

\section{Introduction}

This guideline focuses on the pharmacotherapy of obsessivecompulsive disorder (OCD). OCD is characterised by obsessions and compulsions. A number of other disorders are also characterised by repetitive thoughts and rituals and may also respond to modifications of standard OCD treatment. These so-called OCD spectrum disorders include body dysmorphic disorder (characterised by recurrent concerns with imagined ugliness), hypochondriasis (characterised by recurrent concerns with imagined illness), trichotillomania (characterised by recurrent hair-pulling), and obsessive-compulsive personality disorder. ${ }^{[1]}$ The Diagnostic and Statistical Manual of Mental Disorders, Fifth Edition ${ }^{[2]}$ has a new chapter on obsessive-compulsive and related disorders, which includes several of these conditions.

\section{Diagnosis and clinical characteristics}

Evidence indicates that OCD is commonly underdiagnosed and undertreated. ${ }^{[3]}$ There is also the converse possibility that various disorders with intrusive symptoms, such as post-traumatic stress disorder or generalised anxiety disorder, can be misdiagnosed as OCD. Diagnostic criteria for OCD are provided in Table $1 .^{[4]}$

\section{Assessment}

Most patients with OCD have both obsessions (which increase anxiety) and compulsions (which aim to decrease anxiety), particularly given that the Diagnostic and Statistical Manual of Mental Disorders, Fifth Edition $^{[2]}$ definition of compulsion includes mental rituals. The most common obsessions centre around concerns of contamination, harm, hoarding, and sexual, somatic and religious preoccupations, while the most common compulsions include washing, checking, repeating, ordering, counting, and hoarding. ${ }^{[5]}$ The disorder is highly comorbid with obsessive-compulsive and related disorders, major depressive disorder, anxiety disorders, alcohol dependence, eating disorders and tic disorders. ${ }^{[6,7]}$ Evaluation should include assessment of symptom pattern, severity, and functional impairment. Comorbid Axis I and II disorders, including tic disorders, as well as medical conditions (including pregnancy) and disorders need to be accurately identified. There is growing evidence that OCD and/or tics in some patients, particularly children, are precipitated or exacerbated by streptococcal or other infections. ${ }^{[8]}$

Evaluation of the OCD patient also requires attention to psychosocial factors that may have precipitated or exacerbated OCD symptoms. For example, are family members involved in the patient's rituals? What is the patient's explanatory model of OCD does he or she regard it as a sign of weakness or as evidence of brain dysfunction?

\section{Treatment}

\subsection{Treatment goals}

The goals of treatment of OCD are to reduce symptom frequency and severity and to improve functioning and quality of life. Treatment goals also encompass minimising medication adverse effects, helping the patient develop coping strategies for their OCD and related stressors, and educating the patient and family regarding the disorder and its treatment. ${ }^{[7]}$

\subsection{General aspects of treatment}

In this discussion, we assume that the patient is an adult. Nevertheless, there are increasing data on the pharmacotherapy of OCD in children. ${ }^{[9,10]}$ Indeed, the algorithm (see Fig. 1 below) can readily be adapted for children, bearing in mind considerations such as differences in dosing and differences in risk-benefit determination (e.g. clinicians are less likely to use untested augmentation strategies in children). Consultation with a child psychiatrist may well be indicated in such cases.

\section{Table 1. Criteria for obsessive-compulsive disorder ${ }^{\star}$}

A. Either obsessions or compulsions:

Obsessions as defined by (1), (2), (3), and (4):

1. Recurrent and persistent thoughts, impulses, or images that are experienced, at some time during the disturbance, as intrusive and inappropriate and that cause marked anxiety or distress

2. ${ }^{\dagger}$ The thoughts, impulses, or images are not simply excessive worries about real-life problems

3. The person attempts to ignore or suppress such thoughts, impulses, or images, or to neutralise them with some other thought or action

4. The person recognises that the obsessional thoughts, impulses, or images are a product of his or her own mind (not imposed from without as in thought insertion)

Compulsions as defined by (1) and (2):

1. Repetitive behaviours (e.g. hand washing, ordering, checking) or mental acts (e.g. praying, counting, repeating words silently) obsession, or according to rules that must be applied rigidly

2. The behaviours or mental acts are aimed at preventing or reducing distress or preventing some dreaded event or situation; however, these behaviours or mental acts either are not connected in a realistic way with what they are designed to neutralise or prevent or are clearly excessive

B. At some point during the course of the disorder, the person has recognised that the obsessions or compulsions are excessive or unreasonable

C. The obsessions or compulsions cause marked distress, are time consuming (take more than 1 hour a day), or significantly interfere with the person's normal routine, occupational (or academic) functioning, or usual social activities or relationships

D. If another Axis I disorder is present, the content of the obsessions or compulsions is not restricted to it

E. The disturbance is not due to the direct physiological effects of a substance (e.g. a drug of abuse, a medication) or a general medical condition.

* Adapted from the Diagnostic and Statistical Manual of Mental Disorders, Fourth Edition, Text Revision; DSM-IV-TR. ${ }^{[4]}$ For educational purposes only..

Omitted from the DSM-V $\mathrm{V}^{[2]}$

This has been changed in the DSM- $\mathrm{V}^{[2]}$ 'The disturbance is not better explained by the symptoms of another mental disorder.' 
The initial treatment of OCD can arguably be either medication or psychotherapy as both approaches are efficacious. Several factors may complicate OCD, thus impacting on decisions about the choice of pharmacotherapy and other interventions. The most important factors, along with their treatment implications, are listed below. In addition, prior response to treatment and patient preference are important considerations.

\subsubsection{Severity}

Patients with severe symptoms may require brief hospitalisation to help contain symptoms. In general, however, the principles of behaviour therapy suggest that patients should attempt to continue with their ordinary daily routines where possible.

\subsubsection{Melancholia}

There is some evidence that tricyclic antidepressants (TCAs) may be more effective than selective serotionin reuptake inhibitors (SSRIs) in patients with depression accompanied by melancholic features ${ }^{[1]}$ and in possibly related subgroups such as in-patients with depression, ${ }^{[11-13]}$ although not all evidence is consistent. ${ }^{[14]}$ Melancholic features of depression include loss of pleasure in activities, lack of reactivity to pleasurable stimuli, and various neurovegetative symptoms such as exacerbation of depression in the morning, early-morning awakening, and significant weight loss. The only TCA that is effective in OCD is clomipramine.

\subsubsection{Tourette's disorder}

This disorder is characterised by both motor and vocal tics. Many patients with Tourette's disorder have comorbid OCD. Although this OCD may respond to standard OCD treatments, additional medication that targets the tics (e.g. dopamine blockers such as haloperidol, pimozide, or risperidone) may be necessary for resolution of the range of symptoms that characterise the disorder. ${ }^{[15]}$

\subsubsection{Pregnancy, lactation, menopause}

Pharmacotherapy should ideally be avoided during pregnancy and lactation. Nevertheless, where clinical considerations outweigh the risk of medication, such intervention should be considered after consultation with a specialist. In particular, there is growing literature pointing toward the relative safety of fluoxetine in pregnancy. ${ }^{[16]}$

\subsubsection{Comorbid medical disorders and medications}

Clinicians need to be aware of the multiple interactions between medications used in the treatment of OCD and other medications, as well as the impact of a medication's adverse effects on medical disorders. Fortunately, certain SSRIs have relatively few interactions with other medications, and the SSRIs as a class are well tolerated in most medical disorders.

\subsection{Pharmacological treatment}

Refer to 4.5 and 4.6 below.

\subsection{Non-pharmacological treatment}

Psycho-education as part of the management of OCD is crucial. Similarly, cognitive-behavioural therapy (CBT) is an important aspect of OCD treatment, whether used alone or in combination with medication. ${ }^{[17]}$ CBT for OCD has been delivered in individual, group, and family therapy formats. The number and length of treatment sessions vary across different studies, but some guidelines recommend 13 - 20 weekly sessions for most patients. ${ }^{[7]}$

\subsection{Acute treatment}

Patient motivation and ability to comply with pharmacotherapy and/ or psychotherapy are important considerations in choosing a first-line treatment approach. CBT and serotonin reuptake inhibitors (SRIs) are both considered safe and effective first-line treatments for OCD. ${ }^{[5,7]}$ The decision of whether to commence CBT or an SRI will depend on a number of factors including the nature and severity of symptoms, presence of co-occurring psychiatric and medical comorbidity and their treatments, patients' access to CBT, past treatment history, and patient preference. ${ }^{[5,7]} \mathrm{CBT}$ alone, consisting of exposure and response prevention, is recommended as initial treatment for a patient who is not too depressed, anxious, or severely ill to co-operate with this treatment modality, or who prefers not to take medications and is willing to engage with CBT. Initiating treatment with an SRI is recommended for a patient who has previously responded well to an SRI or other drug, prefers medication treatment or is not suited for CBT. ${ }^{[7]}$

The first line of medication in the treatment of OCD should comprise an SRI. Consistent with growing evidence for the importance of serotonin in OCD, both clomipramine and the SSRIs appear to be more effective than the noradrenergic reuptake inhibitor, desipramine, in the treatment of OCD. ${ }^{[18,19]}$ The efficacy and safety of clomipramine and the SSRIs in the treatment of OCD have been well researched, with studies indicating that at least half of patients will respond to one of these agents. The SRIs are also useful for body dysmorphic disorder, hypochondriasis, obsessive-compulsive symptoms in Tourette's disorder, and possibly (albeit with relatively less robust responses) in hair-pulling disorder (trichotillomania), excoriation (skin-picking) disorder, so-called compulsive sexual behaviour, and pathological gambling. ${ }^{[20,21]}$ Note, however, that other agents may be preferable as first-line options in some of these conditions, e.g. given recent data that $\mathrm{N}$-acetyl-cysteine is useful in hair-pulling disorder, this is an important consideration.

An immediate question, however, is which SRI to use first. Given the apparent lack of differences in efficacy between the SRIs, the sideeffect profile of these agents may be an important issue in considering which agent to use first. Certainly, there are invariably fewer sideeffects during treatment with the SSRIs than during treatment with clomipramine. Therefore, it seems reasonable to suggest that treatment of OCD be initiated with an SSRI.

While all SSRIs appear to have similar efficacy, individual patients may respond well to one medication and not to another. In choosing among the SSRIs, it is important to consider the safety and acceptability of particular side-effects for the patient, potential drug interactions, past treatment response, and the presence of co-occurring general medical conditions. ${ }^{[7]}$ Low doses should initially be used in patients with comorbid panic disorder.

Most patients will not experience substantial improvement until 4 - 6 weeks after initiating medication, and some patients who will ultimately respond will experience little improvement by $8-10$ weeks. ${ }^{[5,7]}$ To determine response to medication, it is important to ask about change in those symptoms initially targeted for treatment. Sideeffects of the medication should also be determined, with particular 
attention to those that patients may be reluctant to disclose (e.g. sexual dysfunction). It may be useful to complete a symptom rating scale (Table 2) ${ }^{[22]}$ to help quantify response to medication.

Patients who are intolerant of a particular medication can of course be switched to another agent. Within the SRIs, adverse effects may not be seen when an alternative SSRI or clomipramine is used.

When there is a poor response to medication, it is important to optimise dosage and duration of the medication. Although some patients with OCD respond to standard doses of SRIs, others require doses that are much higher than in depression. In adults, clomipramine should be increased to approximately $250 \mathrm{mg}$, and the SSRIs should be increased to maximal dosages (e.g. 60 - $80 \mathrm{mg}$ of fluoxetine) bearing in mind recent black box warnings (e.g. citalopram should not be increased higher than $40 \mathrm{mg}$ ). Unfortunately, the likelihood of side-effects also increases at these doses. Electrocardiogram (ECG) monitoring may be necessary when children and adolescents, or patients with pre-existing heart disease, are treated with clomipramine.

Response to SSRIs in OCD may take rather longer than in many other disorders - up to 12 weeks. It is obviously important to give each patient a trial of medication that is of adequate duration. Patients therefore need to be educated that response may take a significant length of time and that they need to remain optimistic even when no change is seen at first.

At the end of a clinical trial of optimal dose and duration, patients should be thoroughly reassessed. There is growing recognition of the importance of residual anxiety symptoms in causing disability and predicting relapse, and of the consequent necessity of aiming for remission of symptoms as the endpoint of treatment. ${ }^{[23]}$ Nevertheless, many OCD patients who are judged 'responders' to medication therapy may continue to experience obsessions and compulsions, albeit with less intensity. In clinical trials, a decrease of 25 - 35\% on the Yale-Brown Obsessive-Compulsive Scale (Y-BOCS) may correspond to a categorical treatment response. ${ }^{[22]}$

\subsection{Maintenance treatment}

In patients where an SRI is effective, maintenance pharmacotherapy should be instituted. Rapid discontinuation of these agents risks the return of symptoms. Nevertheless, a maintenance dose of SSRIs in OCD may be lower than the dose initially required during acute treatment. ${ }^{[21]}$ At least a year of maintenance pharmacotherapy is reasonable. When a decision is made to attempt discontinuation of medication, it is advisable to taper medication off slowly (e.g. by $25 \%$ every 2 months). Concomitant behavioural treatment (exposure therapy and response prevention) during pharmacotherapy may well increase chances of being able to discontinue medication without relapse.

\subsection{Managing partial and non-responders}

Comparison of augmentation with switching strategies in OCD has not been well researched. Augmentation offers the advantage of retaining any possible gains from the first agent, but the potential disadvantages of polypharmacy (more side-effects, drug interactions). ${ }^{[24]}$ Of all the augmentation strategies in the treatment of OCD, perhaps the most important is augmentation of pharmacotherapy with additional psychotherapy. ${ }^{[25]}$

Combined SRI and CBT treatment can be considered when the patient has a co-occurring disorder that is SRI-responsive or has a partial response to monotherapy. Combination of an SRI and CBT may also reduce the chance of relapse when medication is discontinued. In patients who have had a partial response to CBT monotherapy, it may be useful to increase the intensity of treatments. ${ }^{[7]}$

However, when there is a partial response despite an optimum trial of medication, or when there are comorbid tics, it may be useful to consider augmentation. Certainly, in patients with comorbid tics, there is good evidence that augmentation of an SRI with a dopamine blocker can be effective. ${ }^{[26]}$ About one-third to one-half of treatment-refractory OCD patients will have a meaningful treatment response to antipsychotic augmentation. The introduction of the new-generation antipsychotics has led to increased use of these agents in the augmentation therapy of OCD, and they appear useful in treatment-refractory patients even in the absence of comorbid tics. ${ }^{[27-29]}$ Another possible strategy is to supplement an SSRI with a low dose of clomipramine, ${ }^{[30]}$ although careful monitoring of adverse effects and ECGs may be warranted with such a combination. Other augmentation strategies have been suggested, but there are few positive controlled trials. There is also relatively little work on augmentation strategies in OCD-related disorders, although addition of a dopamine blocker may also be useful in some of these patients. ${ }^{[31]}$

When OCD does not respond to a clinical trial of optimal dose and duration, it is useful to reassess a number of factors. The presence of certain features may impact on the choice of the subsequent intervention.

\subsubsection{Compliance}

Clinicians often overestimate the compliance of their patients and it is often useful to check with patients and their families whether medication is being taken as prescribed. Many patients worry that medication is addictive or is a 'crutch'.

\subsubsection{Comorbid substance use}

In patients who fail to respond to pharmacotherapy, the possibility of comorbid substance use should again be considered. There may be a need for withdrawal before tackling the OCD per se. ${ }^{[32,33]}$

\subsubsection{Comorbid personality disorders}

Although SSRIs may be useful, additional interventions such as psychotherapy may be crucial in patients with OCD and comorbid personality disorder. While improvement in OCD symptoms may reduce maladaptive behaviour in comorbid personality disorder, the personality disorder itself may need to be a major target of treatment.

\subsubsection{Underlying medical disorder}

Patients with obsessive-compulsive and related disorders who fail to respond to medication should be thoroughly reassessed for an underlying medical disorder. In OCD in children, the role of streptococcal throat infection may be particularly important.

\subsubsection{Pharmacokinetic issues}

Drug-drug interactions may result in a subtherapeutic dose of the prescribed antidepressant.

\subsubsection{Psychosocial issues}

Psychosocial circumstances that continue to complicate the course of OCD need to be assessed, as these may necessitate appropriate 


\section{Table 2. Yale-Brown Obsessive-Compulsive Scale ${ }^{[22]}$}

Question
'I am now going to ask several questions about your obsessive thoughts.'
(Make specific reference to the patient's target obsessions)

1. Time occupied by obsessive thoughts

Q: How much of your time is occupied by obsessive thoughts? How frequently do the obsessive thoughts occur?

\section{Interference due to obsessive thoughts}

Q: How much do your obsessive thoughts interfere with your social or work (or role) functioning? Is there anything that you don't do because of them?

\section{Distress associated with obsessive thoughts \\ Q: How much distress do your obsessive thoughts cause you?}

\section{Resistance against obsessions}

Q: How much of an effort do you make to resist the obsessive thoughts? How often do you try to disregard or turn your attention away from these thoughts as they enter your mind?

\section{Degree of control over obsessive thoughts}

Q: How much control do you have over your obsessive thoughts? How successful are you in stopping or diverting your obsessive thinking? Can you dismiss them?

The next several questions are about your compulsive behaviours.' (Make specific reference to the patient's target compulsions)

6. Time spent performing compulsive behaviours

Q: How much time do you spend performing compulsive behaviours? How much longer than most people does it take to complete routine activities because of your rituals? How frequently do you perform compulsions?

\section{Answer scale}

$0=$ None

$1=$ Mild, less than 1 hour/day or occasional intrusion.

$2=$ Moderate, 1 to 3 hours/day or frequent intrusion.

$3=$ Severe, greater than 3 and up to 8 hours/day or very frequent intrusion.

$4=$ Extreme, greater than 8 hours/day or near constant intrusion.

$0=$ None.

$1=$ Mild, slight interference with social or occupational activities, but overall performance not impaired.

2 = Moderate, definite interference with social or occupational performance, but still manageable.

$3=$ Severe, causes substantial impairment in social or occupational performance.

$4=$ Extreme, incapacitating.

$0=$ None.

$1=$ Mild, not too disturbing.

2 = Moderate, disturbing, but still manageable.

$3=$ Severe, very disturbing.

4 = Extreme, near constant and disabling distress.

$0=$ Makes an effort to always resist, or symptoms so minimal doesn't need to actively resist.

$1=$ Tries to resist most of the time.

2 = Makes some effort to resist.

3 = Yields to all obsessions without attempting to control them, but does so with some reluctance.

4 = Completely and willingly yields to all obsessions.

$0=$ Complete control.

$1=$ Much control, usually able to stop or divert obsessions with some effort and concentration.

$2=$ Moderate control, sometimes able to stop or divert obsessions.

3 = Little control, rarely successful in stopping or dismissing obsessions, can only divert attention with difficulty.

$4=$ No control, experienced as completely involuntary, rarely able to even momentarily alter obsessive thinking.

$0=$ None.

1 = Mild (spends less than 1 hour/day performing compulsions), or occasional performance of compulsive behaviours.

2 = Moderate (spends from 1 to 3 hours/day performing compulsions), or frequent performance of compulsive behaviours.

$3=$ Severe (spends more than 3 and up to 8 hours/day performing compulsions), or very frequent performance of compulsive behaviours.

4 = Extreme (spends more than 8 hours/day performing compulsions), or near constant performance of compulsive behaviours (too numerous to count).

continued. 


\section{for 23 12

Table 2 (continued). Yale-Brown Obsessive-Compulsive Scale ${ }^{[22]}$

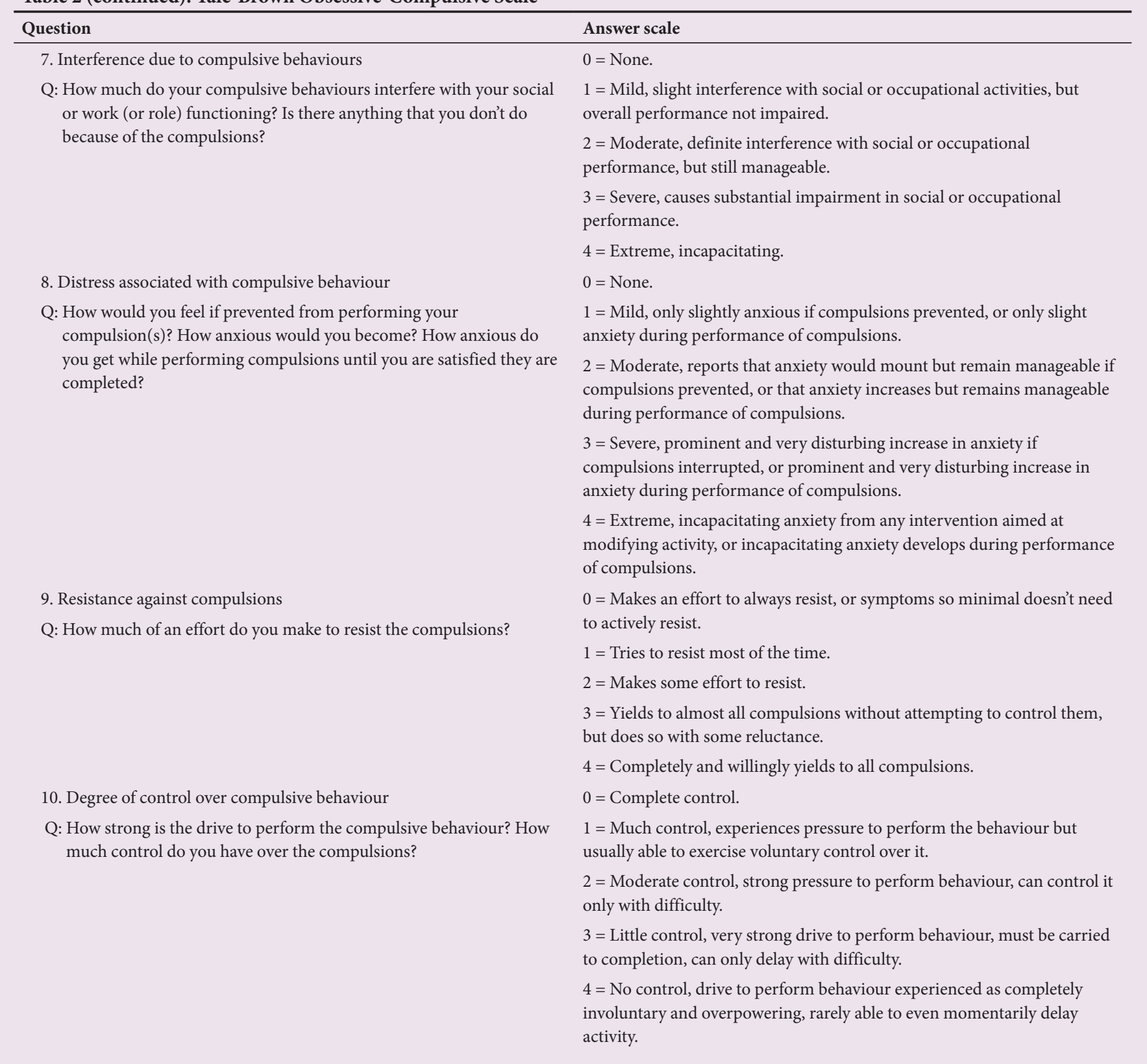

intervention. In particular, the participation of friends and family in rituals may serve to derail treatment.

After the failure of an adequate clinical trial of medication in a patient where reassessment sheds no light on any further unresolved factors, a different agent should be used. Although an SRI has less chance of being effective in patients who have already failed a number of trials of other SRIs, some of these patients (approximately one-third of non-responders to initial SRI monotherapy) will in fact ultimately respond to a new SRI. ${ }^{[34]}$ Given the possible superiority of clomipramine in certain cases of OCD and depression, it may be argued that all OCD patients who have failed to respond to one or more of the SSRIs deserve a trial of clomipramine. ${ }^{[35]}$ While results of studies correlating plasma drug levels and therapeutic response in
OCD have been mixed, in the case of clomipramine obtaining drug levels at high doses may be useful. Anecdotal experience suggests that certain non-SRI agents, such as the classic monoamine oxidase inhibitors and venlafaxine, may on occasion be effective in treatmentresistant $\mathrm{OCD} .^{[36]}$ Recent trials of intravenous clomipramine also show efficacy in treatment-resistant OCD. ${ }^{[37]}$

For patients who have failed multiple medication and behavioural treatments (including intensive partial or full hospitalisation programmes), ${ }^{[38]}$ and where severity of the disorder is marked, neurosurgery should also be considered. ${ }^{[39]}$ Several studies have suggested that specific lesions to or deep-brain stimulation of components of corticostriatal and related pathways may lead to significant reduction in OCD symptoms in treatment-refractory 
patients. Patients can be referred to specialised centres for such treatments.

\section{Algorithm}

Fig. 1 outlines the treatment.

\section{Summary points}

- $\mathrm{CBT}$ and the serotonin reuptake inhibitors (SRIs), clomipramine and the SSRIs, are efficacious and safe first-line treatments for OCD.

- Whether to commence CBT or an SRI will depend on the nature and severity of symptoms, presence of co-occurring psychiatric and medical comorbidities and their treatments, a patient's access to CBT, past treatment history, and patient preference.

- CBT alone, consisting of exposure and response prevention, is recommended as first-line for a patient who is not too depressed, anxious, or severely ill to co-operate with this treatment modality, or who prefers not to take medications and is willing to engage with CBT.

- SRI first-line treatment is recommended for a patient who has previously responded well to an SSRI or other drug, prefers medication treatment, or is not suited for CBT.

- Most patients will not experience substantial improvement until 4 - 6 weeks after initiating medication, and some patients who ultimately respond will experience little improvement by 8 - 10 weeks.

- Although some patients with OCD respond to standard doses of SRIs, others require doses that are much higher than those used for depression. In adults, clomipramine should be increased to approximately 250 $\mathrm{mg}$, and the SSRIs should be increased to maximal safe dosages (e.g. 60 - $80 \mathrm{mg}$ of fluoxetine).

- At least a year of maintenance pharmacotherapy is reasonable in patients who respond to medication.

- CBT (exposure and response prevention) can be used alone or in combination with medication. Psycho-education is also crucial.

- When there is a partial response to an optimal trial of medication, or when there are comorbid tics, it may be useful to consider augmentation. Many OCD patients will have a meaningful treatment response to antipsychotic augmentation.

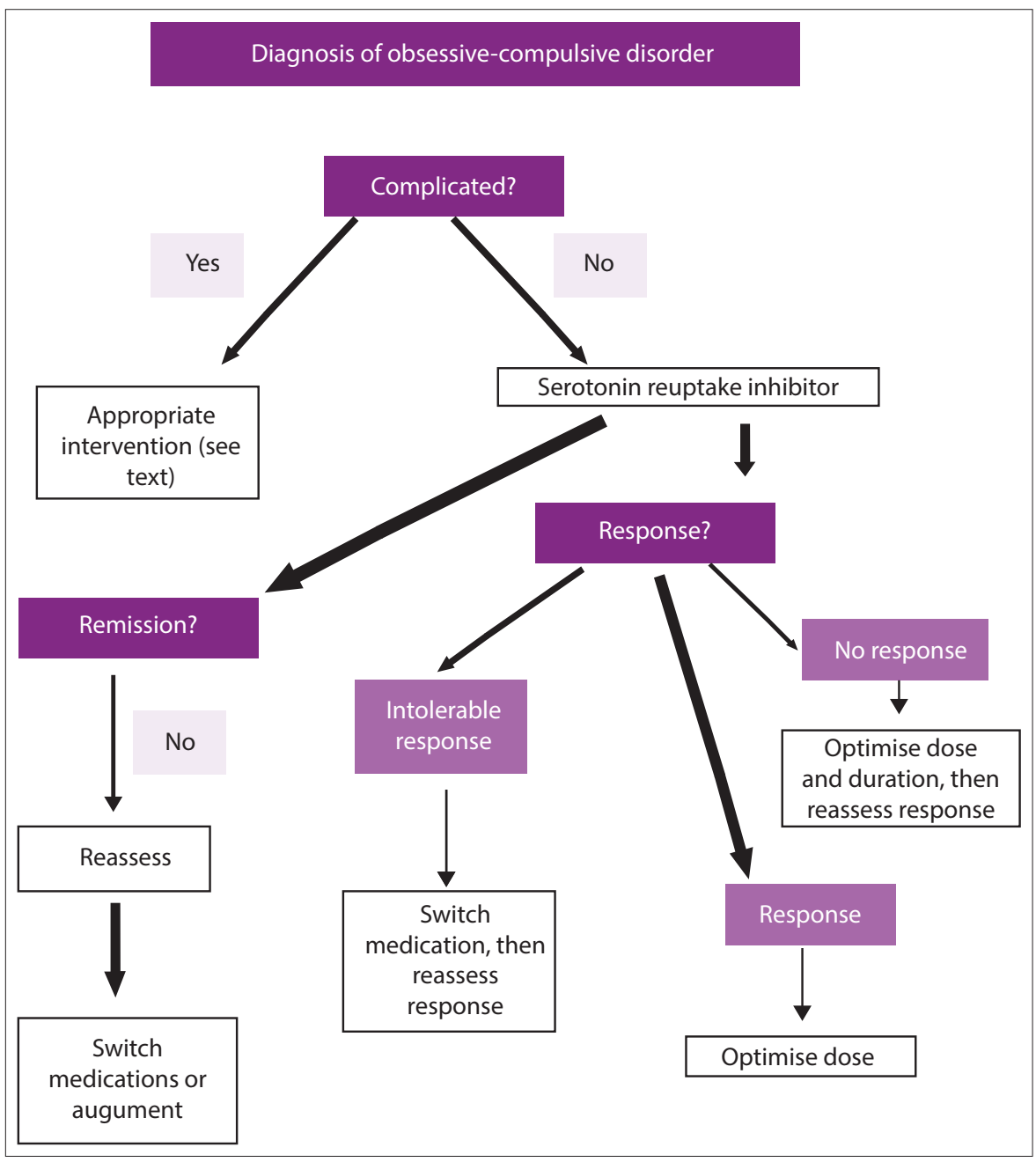

Fig. 1. Algorithm for pharmacotherapy of obsessive-compulsive disorder ${ }^{[00]}$

\section{Additional reading}

- Jefferson JW, Altemus M, Griest JH, et al. An algorithm for the pharmacologic treatment of obsessive compulsive disorder. Psychopharmacology Bulletin 1996;31:487-490.

- March JS, Frances A, Carpenter D, Kahn D. Treatment of obsessive-compulsive Disorder. J Clin Psychiatry 1997;S4:1

- Stein DJ, Emsley RA. Treatment of the difficult obsessivecompulsive disorder patient. In: Lader M, Naber D, eds. Difficult Clinical Problems in Psychiatry. London: Martin Dunitz, 1999.

- Stein DJ, Hollander E. Serotonin reuptake inhibitors in obsessive-compulsive disorder and related disorders. In: Feighner J, Boyer WF, eds. Selective Serotonin Reuptake Inhibitors: Advances in Basic Research and Clinical Practice. 2nd ed. New York: John Wiley, 1996.

\section{References}

1. Stein DJ, Hollander E. Serotonin reuptake inhibitors in obsessive-compulsive disorder and related disorders. In: Feighner J, Boyer WF, eds. Selective Serotonin Reuptake Inhibitors: Advances in Basic Research and Clinical Practice, 2nd ed. New York: John Wiley, 1996.

2. American Psychiatric Association. Diagnostic and Statistical Manual of Mental Disorders, Fifth Edition. Washington, DC: American Psychiatric Association, 2013.

3. Stein DJ, Hollander E, Rowland, et al. Quality of life and pharmaco-economic aspects of obsessive-compulsive disorder: A South African survey. S Afr Med J 1996;86:1579-1585.
4. American Psychiatric Association. Diagnostic and Statistical Manual of Mental Disorders, Fourth Edition, Text Revision (DSM-IV-TR). Washington, DC: American Psychiatric Association, 2000.

5. Bandelow B, Zohar J, Hollander E, et al. WFSBP Task Force on Treatment Guidelines for Anxiety, Obsessive-Compulsive and Post-Traumatic Stress Disorders. World Federation of Societies of Biological Psychiatry (WFSBP) guidelines for the pharmacological treatment of anxiety, obsessive-compulsive and post-traumatic stress disorders - first revision. World Journal of Biological Psychiatry 2008;9:248-312. [http:// dx.doi.org/10.1080/15622970802465807]

6. Pigott TA, L'Heureux F, Dubbert B, et al. Obsessive compulsive disorder: Comorbid conditions. J Clin Psychiatry 1994;55:15-32.

7. Koran LM, Hanna GL, Hollander E, et al. Practice guideline for the treatment of patients with obsessive-compulsive disorder. Am J Psychiatry 2007;164:5-53

8. Swedo SE, Leonard HL, Garvey M, et al. Pediatric autoimmune neuropsychiatric disorders associated with streptococcal infections: Clinical description of the first 50 cases. Am J Psychiatry 1998;155:264-271.

9. Geller DA, Biederman J, Stewart SE, et al. Which SSRI? A meta-analysis of pharmacotherapy trials in pediatric obsessive-compulsive disorder. Am J Psychiatry 2003;160:1919-1928.

10. King RA, Leonard H, March J, Work Group on Quality Issues. Practice parameters for the assessment and treatment of children and adolescents with obsessive-compulsive disorder J Am Acad Child Adolesc Psychiatry 1998;37(S10):27-45. 


\section{for

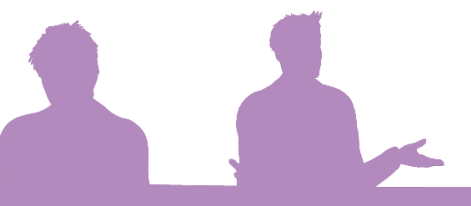 $A 2$

11. Roose SP, Glassman AH, Attia E, et al. Comparative efficacy of selective serotonin reuptake inhibitors and tricyclics in the treatment of melancholia. Am J Psychiatry 1994;151:1735-1739.

12. Anderson IM. Selective serotonin reuptake inhibitors versus tricyclic antidepressants: A metaanalysis of efficacy and tolerability. J Affect Disord 2000;58:19-36.

13. Clerc GE, Ruimy P, Verdeau-Palles J. A double-blind comparison of venlafaxine and fluoxetine in patients hospitalized for major depression and melancholia. The Venlafaxine French Inpatient Study Group. Int Clin Psychopharmacol 1994;9:139-143.

14. Joyce PR, Mulder RT, Luty SE, et al. A differential response to nortriptyline and fluoxetine in melancholic depression: The importance of age and gender. Acta Psychiatr Scand 2003;108:20-23. [http://dx.doi.org/10.1034/j.1600-0447.2003.00120.x]

15. Hawkridge S, Stein DJ, Bouwer C. Combining neuroleptics with serotonin specific reuptake inhibitors in Tourette's syndrome. J Am Acad Child Adolesc Psychiatry 1996;35:703-704.

16. Nulman I, Rovet J, Stewart DE, et al. Neurodevelopment of children exposed in utero to antidepressant drugs. New Engl J Med 1997;336:258-262.

17. Goodman WK, Price LH, Rasmussen SA, et al. The Yale-Brown Obsessive-Compulsive Scale. I. Development, use, and reliability. Arch Gen Psychiatry 1989;46:1006-1011.

18. Stein DJ, Spadaccini E, Hollander E. Meta-analysis of pharmacotherapy trials for obsessive compulsive disorder. Int Clin Psychopharmacology 1995;10:11-18.

19. Ackerman DL, Greenland S. Multivariate meta-analysis of controlled drug studies for obsessive-compulsive disorder. J Clin Psychopharmacol 2002;22:309-317. [http://dx.doi. org/10.1097/00004714-200206000-00012]

20. Stein DJ. Neurobiology of the obsessive-compulsive spectrum of disorders. Biological Psychiatry 2001;47:296-304.

21. Pato MT, Hill JL, Murphy DL. A clomipramine dosage reduction study in the course of longterm treatment of obsessive compulsive disorder patients. Psychopharmacology Bulletin 1990;26:211-214.

22. Broocks A, Hohagen F. Psychotherapy in OCD. In: Fineberg N, Marazziti D, Stein DJ, eds Obsessive-Compulsive Disorder: A Practical Guide. London: Martin Dunitz, 2001.

23. Ballenger JC. Treatment of anxiety disorders to remission. J Clin Psychiatry 2001;62(S12):5-9.

24. Fava M. Augmentation and combination strategies in treatment-resistant depression. J Clin Psychiatry 2001;62(S18):4-11.

25. Stein DJ, Fineberg N, Seedat S. An integrated approach to the treatment of OCD. In: Fineberg N, Marazziti D, Stein DJ, eds. Obsessive-Compulsive Disorder: A Practical Guide. London: Martin Dunitz, 2001
26. McDougle CJ, Goodman WK, Leckman JF. Haloperidol addition in fluvoxamine-refractory obsessive-compulsive disorder: A double-blind placebo-controlled study in patients with and without tics. Arch Gen Psychiatry 1994;51:302-308.

27. McDougle CJ, Epperson CN, Pelton GH, et al. A double-blind, placebo-controlled study of risperidone addition in serotonin reuptake inhibitor-refractory obsessive-compulsive disorder. Arch Gen Psychiatry 2000;57:794-802. [http://dx.doi.org/10.1001/archpsyc.57.8.794]

28. Komossa K, Depping AM, Meyer M, et al. Second-generation antipsychotics for obsessive compulsive disorder. Cochrane Database of Systematic Reviews. 2010;12:CD008141. [http:// dx.doi.org/10.1002/14651858.CD008141]

29. Bloch MH, Landeros-Weisenberger A, Kelmendi B, et al. A systematic review: Antipsychotic augmentation with treatment refractory obsessive-compulsive disorder. Mol Psychiatry 2006;11:622-632.

30. Ravizza L, Barzega G, Bellino S, et al. Therapeutic effect and safety of adjunctive risperidone in refractory obsessive-compulsive disorder (OCD). Psychopharmacology Bulletin 1996;32:677-682.

31. Stein DJ, Bouwer C, Hawkridge S, et al. Risperidone augmentation of serotonin reuptake inhibitors in obsessive-compulsive and related disorders. J Clin Psychiatry 1997;58:119-122.

32. Castenada R, Sussman N, Westreich L, et al. A review of the effects of moderate alcohol intake on the treatment of anxiety and mood disorders. J Clin Psychiatry 1996;57:207-212.

33. Schadé A, Marquenie LA, van Balkom AJLM, et al. Do comorbid anxiety disorders in alcoholdependent patients need specific treatment to prevent relapse? Alcohol Alcohol 2003;38:255-262. [http://dx.doi.org/10.1093/alcalc/agg062]

34. Marazziti D, Dell'Osso L, Gemignani A, et al. Citalopram in refractory obsessive-compulsive disorder: An open study. International Clinical Psychopharmacology 20001;16:215-219.

35. Hollander E, Mullen L, DeCaria CM, et al. Obsessive compulsive disorder, depression, and fluoxetine. J Clin Psychiatry 1991;52:418-422.

36. Ananth J, Burgoyne K, Smith M, et al. Venlafaxine for treatment of obsessive-compulsive disorder. Am J Psychiatry 1995;152:1832.

37. Koran LM, Sallee FR, Pallanti, S. Rapid benefit of intravenous pulse loading of clomipramine in obsessive-compulsive disorder. Am J Psychiatry 1997;154:396-401.

38. Bystritsky A, Munford PR, Rosen RM, et al. A preliminary study of partial hospital management of severe obsessive-compulsive disorder. Psychiatr Serv 1996;47:170-174.

39. Martuza RL, Chiocca EA, Jenike MA, et al. Stereotactic radiofrequency thermal cingulotomy for obsessive-compulsive disorder. J Neuropsychiatry 1990;2:331-336.

40. Stein DJ, Seedat S, Niehaus DJH, et al. Psychiatric medications in primary care: Algorithms and guidelines. Cape Town: University of Stellenbosch: Mental Health Information Centre, 2005:77. 